\title{
Physical Fitness of Basketball and Volleyball Players of Kolkata, India
}

\author{
Sohini Basu, Anindita Singha Roy, Rishna Dalui, Amit Bandyopadhyay*
}

\section{Sohini Basu, Anindita Singha Roy, Rishna Dalui, Amit Bandyopadhyay*}

Sports and Exercise Physiology Laboratory, Department of Physiology, University of Calcutta, University Colleges of Science and Technology, 92 A.P.C. Road, Kolkata, INDIA.

\section{*Correspondence}

\section{Dr. Amit Bandyopadhyay M.Sc., Ph.D., FICN}

Assistant Professor, Sports and Exercise Physiology Laboratory, Department of Physiology, University of Calcutta, University Colleges of Science and Technology, 92 A.P.C. Road, Kolkata, 700009, INDIA.

Phone: +91 8334870640

Email: bamit74@yahoo.co.in

\section{History}

- Submission Date: 09-08-2019;

- Review completed: 25-10-2019;

- Accepted Date: 06-11-2019.

\section{DOI : 10.5530/ijcep.2019.6.4.31}

\section{Copyright}

(C) 2019 Phcog.Net. This is an openaccess article distributed under the terms of the Creative Commons Attribution 4.0 International license.

\begin{abstract}
Background and Aim: Data of fitness profile parameters in Indian basketball and volleyball players are scanty. Present study aimed to evaluate the fitness profile parameters of the volleyball and basketball players and compare the data between the groups and with their overseas and sedentary counterparts. Methods: Volleyball $(n=40)$ and basketball $(n=40)$ players belonging to the age group of 18-30 years were recruited from Kolkata, India in addition to their sedentary counterparts $(n=30)$ who were recruited from the same locality where the players reside. Standard procedures were adopted to evaluate the fitness profile parameters. Statistical analyses comprised of ANOVA followed by Bonferroni's post-hoc analysis with the level of significance set at $p<0.05$. Results: Basketball players had significantly higher anaerobic power and BMI, \% body fat and total body fat than the volleyball players, whereas, agility, body density and \% LBM were significantly higher in volleyball players. Conclusion: Inter-group difference among the experimental group individuals may be attributed to the variation in the physical and physiological demands pertaining to their specific sport as well as difference in their training modules. Greater fitness in the studied players in comparison to sedentary control individuals was attributed due to their regular involvement in training.

Key words: $\mathrm{VO}_{2} \max$, Anaerobic power, Fat percentage, Basketball players, Volleyball players.
\end{abstract}

\section{INTRODUCTION}

Physical fitness is indispensable in order to excel in any sport. Physical fitness is the ability to carry out daily tasks (work and play) with vigour and alertness, without undue fatigue and with ample energy to enjoy leisure-time pursuits and to meet unforeseen emergencies. ${ }^{[1]}$ Proper nutrition, exercise and adequate rest account for the achievement and improvement of physical fitness. Participation in court sports as that of basketball and volleyball seem to accentuate the benefits of physical fitness. Both these ball games have gained immense popularity and are practically played in every nation at varying levels of competence. Success in these sporting endeavours is commonly determined by the interaction of a combination of factors including genetics, physical, mental, technical and tactical training and preparation as well as good lifestyle and personal attributes. Among them, physical abilities of the players are more important as these have marked effects on the skill of players and the tactics of the teams because all ball games require repeated maximum exertion such as dashing and jumping. ${ }^{[2]}$ Such physical abilities are vital to both volleyball and basketball players in accomplishing higher levels of performance.

Basketball is considered as a high-intensity sport with significant physical contact, high speed and constant jumps and shifts. ${ }^{[3]}$ Agility, apart from other physical fitness parameters such as anaerobic endurance and speed of movement has been considered as vital factors necessary to improve the performance of basketball. ${ }^{[4]}$

The characteristics of volleyball, including speed, jumping for spikes and blocks at high intensities over a short period of time result in moulding of fast and agile athletes who possess a high level of muscular strength and aerobic fitness. ${ }^{[5]}$ Fitness of Volleyball players relies on their force, power output and jumping ability ${ }^{[6]}$ In addition to somatic traits, aspects such as experience, body composition, endurance, balance between anaerobic power and aerobic power are the essential factors that play pivotal role in improving the skill and performance of Volleyball players. ${ }^{[7]}$

Data pertaining to some of the fitness profile parameters in case of the basketball and volleyball players although available in the Indian context, however they are not adequate and do not provide the detailed information. Moreover, data with respect to the basketball players particularly belonging to the Eastern zone of the Indian subcontinent are absent.

The present study was therefore aimed to assess and eters among the male basketball and male volleyball players of Kolkata, India. Further, the study attemptcompare certain discerning fitness profile param-

Cite this article: Basu S, Roy AS, Dalui R, Bandyopadhyay A. Physical Fitness of Basketball and Volleyball Players of Kolkata, India. Int J Clin Exp Physiol. 2019;6(4):111-7. 
ed to compare the data with their sedentary as well as both national and international counterparts.

\section{MATERIALS AND METHODS}

\section{Study Design}

Participants for the study visited the laboratory for three occasions with at least seven days interval between the consecutive visits. On the first day of visit, in an effort to allay all apprehensions, Familiarization Trial was conducted whereby the subjects were explained and demonstrated regarding the experimental protocol. On the second and third days of the visit, data pertaining to the subjects were collected by means of conducting two Experimental Trial sessions. During the first Experimental Trial (i.e., on the second day of visit), measurements related to body height, body weight, skinfold thickness and girths alongside motor fitness components such as flexibility, agility as well as high intensity effort of the subjects were recorded. Further, on the third day of visit, by virtue of the second Experimental Trial, parameters such as the pre-exercise heart rate, blood pressure, $\mathrm{VO}_{2}$ max and Vertical Jump Test (VJT) score of the subjects were recorded. The study was approved by the Human Ethical Committee, Department of Physiology, University of Calcutta. All the subjects provided written informed consent for volunteering in the study.

\section{Selection of Subjects}

Male volleyball $(n=40)$ and basketball players $(n=40)$ belonging to the age group of 18-30 years were recruited from the Sports Association camps and various eminent sports academies in and around Kolkata, India. Conversely, their age-matched, healthy sedentary male control counterparts were appointed from the postgraduate section of University of Calcutta. The inclusion criteria for the participants were that they belonged to same age bracket, hailed from similar socio-economic backgrounds, were non-smokers and had no history of any major diseases. Those subjects who were undergoing medication for treatment of any chronic ailment were excluded from taking part in the study.

Health status, personal demographic data in addition to consent for participation in the study was obtained from the subjects through filling up of questionnaire.

\section{Preparation of Subjects}

Calculation for the age of the subjects was done based on the nearest year from the date of birth as retrieved from their Photo ID issued by the Government of India. Prior to the trial, the subjects were advised to have light breakfast. They reported at the laboratory around $9 \mathrm{AM}$ and were asked to take rest for half an hour. Measurements of body height and body mass were taken with the subject standing barefoot and wearing minimum clothing on a weighing machine built-in with height measuring rod (Avery India Ltd, India) having an accuracy of $\pm 0.50 \mathrm{~cm}$ and \pm 0.1 $\mathrm{kg}$, respectively. Body Surface Area (BSA) and body mass index (BMI) were calculated by the following formulae:

$$
\text { BSA }\left(\mathrm{m}^{2}\right)=(\text { Body mass in } \mathrm{kg})^{0.425} \times(\text { Body height in } \mathrm{cm})^{0.725} \times 0.007184^{[8]}
$$$$
\text { BMI }\left(\mathrm{kg} / \mathrm{m}^{2}\right)=(\text { Body mass in } \mathrm{kg}) \div(\text { Stature in } \mathrm{m})^{2[9]}
$$

\section{Determination of Body Composition}

Measurement of the skinfolds was done with the help of Holtain skinfold calliper (Holtain Ltd., UK) having the constant tension for determination of the several components of body composition employing the following equations:

Body Density or BD $(\mathrm{gm} / \mathrm{cc})=1.1631-0.0632(\mathrm{X})^{[10]}$

[Where X= log (Biceps + Triceps + Subscapular + Suprailiac)]

$\%$ Body fat or $\%$ fat $=(495 / \mathrm{BD})-450^{[11]}$
The following equations were employed for calculations of the subsequent measurements of total body fat, percentage of lean body mass and lean body mass:

$$
\begin{aligned}
& \text { Total Body Fat or FM }(\mathrm{kg})=(\% \text { fat / 100) x Body weight }(\mathrm{kg}) \\
& \text { \%Lean Body Mass or \%LBM }(\%)=100-\% \text { fat } \\
& \text { Lean Body Mass or LBM }(\mathrm{kg})=\text { Body Mass }(\mathrm{kg})-\mathrm{FM}(\mathrm{kg})
\end{aligned}
$$

\section{Determination of Waist:Hip Ratio (WHR)}

Waist circumference: Waist circumference was measured at the midpoint between the lower border of the rib cage and the iliac crest. It was measured in centimetre by placing the tape horizontally on the trunk at the level of the waistline of the subject.

Hip circumference: Hip circumference was measured horizontally at the level of gluteus. The tape was placed at the gluteus and its end met on the lateral surface of the thigh of the subject. Measurement was done in $\mathrm{cm}$. Thus, WHR was derived as follows: ${ }^{[12]}$

$$
\frac{\text { Waist circumference }(\mathrm{cm})}{\text { Hip circumference }(\mathrm{cm})}
$$

\section{Determination of Maximum Oxygen Uptake or $\mathrm{VO}_{2} \max$}

Incremental bicycle exercise was performed followed by analysis of the aliquot of the expired gas through Scholander micro-gas analyzer to determine the cardiorespiratory fitness of the subject in terms of $\mathrm{VO}_{2} \mathrm{max}$. [13]

\section{Measurement of Agility}

Instructions were given to the participants for completing a shuttle run as quickly as possible between two parallel lines placed at 30 feet apart. Behind the line opposite to the beginning line, two wooden blocks were positioned. Participants initiated the run from the start line to the other line and continued by picking up one block and going back to place it behind the start line. In the next move, the participant again ran to pick up the second block and returned to keep it back across the start line as before. Recording was done with respect to the total time taken for completion of the entire shuttle run test with the help of a stopwatch. ${ }^{[13]}$

\section{Determination of Flexibility}

Flexibility was evaluated by employing the modified sit and reach test. Participants were instructed to sit barefoot on the floor with outstretched legs. By keeping both the knees pressed and locked flat to the floor, subjects placed the soles of their feet flat against a wooden box. With the palm facing downwards, hands were either placed side by side or on top of each other and the subjects were asked to bend for the sake of reaching forward along the measuring line as far as they could. Further, it was ensured so that the hands remained at the same level, not one reaching further forward than the other did. The moment the subjects reached out the maximum possible distant point as indicated in the measuring scale, the distance was recorded. ${ }^{[13]}$

\section{Determination of High-Intensity Effort (HIE)}

A 60 -yard dash test which comprises of a shuttle run test of progressing distances was conducted to determine the High-Intensity Effort (HIE) for the subjects. In three yard lines, three marker cones separated at a distance of 5 yards apart were kept. The test took off by the participants beginning to run from one end, ran for 5 yards and returned to the start line, then again rushed immediately to the 10 yards mark and came back to the start line and ultimately rushed to the 15 yards mark and came back to finish off at the beginning spot. Each participant was told to touch the line at each run with their fingertips constituting five touches 
during each step and thus completed a total of 60 yards distance. A stopwatch was used to record the total running time. ${ }^{[13]}$

\section{Determination of Vertical Jump Test (VJT) Score}

VJT score was used to assess the explosive strength of the leg muscles. With the arm extended fully over the head, the subject was asked to stand erect adjacent to a wall and attempted to reach the topmost position with the fingers extended completely and smeared in colour with the palm facing the wall. Flat feet were kept on the floor. Retaining this posture, a note was kept of the spot marked with the most extended tip of the finger. Next, the subject performed a spot jump with best effort to reach as high as possible by means of touching the wall at the highest point of the jump. Marking was also made with respect to this spot and the difference between the marks was taken into account as the vertical jump height. ${ }^{[9]}$

\section{Determination of Reaction Time}

The reaction time of the subjects was measured by means of Ruler Drop Test. The ruler was held by the experimenter between the outstretched index finger and thumb of the subject's dominant hand, so that the top of the subject's thumb was level with the zero centimetre line on the ruler. The subject was instructed to catch the ruler as soon as possible after it had been released. The ruler was released and the subject caught the ruler between his index finger and thumb as quick as possible. The distance between the bottom of the ruler and the top of the subject's thumb where the ruler had been caught was recorded. The test was repeated 2 more times and the average value was used in the assessment. The algorithm for calculating reaction time, is $\mathrm{t}(\mathrm{sec})=\sqrt{\frac{2 d}{a}}$ where $\mathrm{d}=$ distance in $\mathrm{m}, \mathrm{a}=$ acceleration due to gravity $=9.81 \mathrm{~m} / \mathrm{sec}^{2} \cdot{ }^{[14]}$

\section{Determination of Handgrip Strength}

The instrument scale was set at zero. The subject was asked to stand with the shoulder adducted and neutrally rotated and the elbow in full extension and hold the dynamometer in vertically downward position without support, not touching the subject's trunk and press it with maximum force. This process was repeated with both arms (right and left), for thrice. The readings were noted. Isometric strength was tested by measuring the peak force applicable at the specific joint angle at which the test was measured..$^{[9]}$

\section{Statistical Analysis of Data}

The data have been presented as Mean \pm SD. In order to test the significance with respect to the mean values of the measured variables among different group, one way Analysis of Variance (ANOVA) was performed. Further, after detection of significant main effect, Bonferroni's post-hoc analysis was conducted for locating where the specific mean differences were laid. The level of significance was set at $p<0.05$. Statistical treatment of the data was performed by employing the Statistical Package for Social Sciences (SPSS) Version 21 software.

\section{RESULTS}

Age did not depict any significant inter-group variation in the studied population but body height, body weight and BSA were significantly higher for both the basketball as well as volleyball players when compared against their age-matched healthy sedentary counterparts (Table 1). However, physiological variables such as pre-exercise heart rate and diastolic blood pressure were significantly lower in case of the experimental groups (basketball and volleyball) in contrast to the control (sedentary) group.

Systolic blood pressure was significantly lower for only the basketball group comparable with the sedentary group. Moreover, a significant inter-group variation was noted for BMI between the basketball and volleyball players. Motor ability parameters, e.g., agility and explosive power as represented by VJT score was significantly different for both the basketball and volleyball players when compared with their sedentary counterparts. There was a significant inter-group variation for the agility parameter between the basketball and volleyball players. Other parameters related to reaction time, anaerobic power and $\mathrm{VO}_{2}$ max showed significant difference from the sedentary group. Both the basketball players and volleyball players showed greater $\mathrm{VO}_{2}$ max in addition to better anaerobic power and reaction time comparable with their sedentary counterparts. Moreover, specific intra-group differences were found in case of reaction time and anaerobic power as represented by HIE score between the basketball and volleyball players (Table 2).

Figure 1, 2 and 3 represent the waist circumference and hip circumference, waist:hip ratio in addition to the skinfold measurement of the subjects in the studied population respectively. The waist girth measurement and skinfold measurement of the calf in case of the volleyball players were significantly lower in contrast to their sedentary counterparts. Both the basketball as well as the volleyball players depicted significantly lower waist:hip ratio when compared against the sedentary group individuals. Further, the skinfold measurements related to biceps, triceps and mid thigh were significantly different for both basketball and volleyball players compared to the sedentary group. A significant intra-group variation was noted for the Suprailiac skinfold between the basketball and volleyball players. However, hip girth, Subscapular and Supraspinale skinfolds did not reveal any significant difference.

Lean Body Mass (LBM) was significantly higher for the basketball and volleyball players when compared against their sedentary counterparts (Table 3). Basketball players also showed significantly higher total fat and significantly lower percentage of lean body mass in contrast to their sedentary counterparts.

Significant intra-group variations were also noted in terms of body density, percentage of body fat, total fat and percentage of lean body mass between the basketball players and volleyball players. Figure 4 illustrated the handgrip strengths of the right hand and left hand of the subjects.

Table 1: Physical and physiological parameters of the different groups of subjects.

\begin{tabular}{|c|c|c|c|c|c|c|c|c|}
\hline \multirow[t]{2}{*}{ Group } & \multirow[t]{2}{*}{$\begin{array}{l}\text { Age } \\
\text { (yrs) }\end{array}$} & \multirow[t]{2}{*}{$\begin{array}{l}\text { Height } \\
(\mathrm{cm})\end{array}$} & \multirow{2}{*}{$\begin{array}{l}\text { Body } \\
\text { Weight } \\
\text { (kg) }\end{array}$} & \multirow[t]{2}{*}{$\begin{array}{l}\text { BSA } \\
\left(m^{2}\right)\end{array}$} & \multirow[t]{2}{*}{$\begin{array}{c}\text { BMI } \\
\left(\mathrm{kg} / \mathrm{m}^{2}\right)\end{array}$} & \multirow{2}{*}{$\begin{array}{l}\text { Pre-exercise } \\
\text { heart rate } \\
\text { (beats/min) }\end{array}$} & \multicolumn{2}{|c|}{$\begin{array}{l}\text { Blood pressure } \\
\text { ( } \mathrm{mm} \text { of } \mathrm{Hg})\end{array}$} \\
\hline & & & & & & & Systolic & Diastolic \\
\hline Sedentary $(n=30)$ & $23.13 \pm 1.70$ & $167.22 \pm 4.54$ & $60.58 \pm 9.80$ & $1.66 \pm 0.13$ & $21.63 \pm 2.99$ & $78.6 \pm 5.88$ & $117.2 \pm 6.64$ & $76.8 \pm 6.09$ \\
\hline Basketball $(\mathrm{n}=40)$ & $24.18 \pm 5.51$ & $178.98 \pm 7.87^{\star}$ & $71.39 \pm 9.98^{*}$ & $1.87 \pm 0.15^{\star}$ & $22.26 \pm 2.56$ & $67.65 \pm 7.79^{*}$ & $112.18 \pm 7.59^{*}$ & $72.50 \pm 8.04^{*}$ \\
\hline Volleyball $(n=40)$ & $22.63 \pm 6.32$ & $179.33 \pm 7.71^{*}$ & $66.7 \pm 10.19^{*}$ & $1.82 \pm 0.16^{*}$ & $20.70 \pm 2.68 \#$ & $69.13 \pm 8.66^{*}$ & $114.40 \pm 8.30$ & $72.00 \pm 7.30^{*}$ \\
\hline
\end{tabular}

Data are Mean \pm SD: : BSA: Body surface area; BMI: Body mass index.

${ }^{*} p<0.05$ when compared with the sedentary control group

$\# p<0.05$ when compared between basketball and volleyball group 
Table 2: Motor ability parameters, reaction time, anaerobic power and aerobic capacity in different groups of subjects.

\begin{tabular}{|c|c|c|c|c|c|c|}
\hline Group & $\begin{array}{l}\text { Agility } \\
\text { (sec) }\end{array}$ & $\begin{array}{l}\text { Motor Abilities } \\
\text { Flexibility } \\
\text { (cm) }\end{array}$ & $\begin{array}{l}\text { Explosive Power } \\
\text { (cm) }\end{array}$ & $\begin{array}{c}\text { Reaction Time } \\
\text { (sec) }\end{array}$ & $\begin{array}{c}\text { Anaerobic Power } \\
\text { (sec) }\end{array}$ & 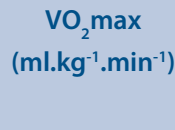 \\
\hline Sedentary $(n=30)$ & $12.27 \pm 0.26$ & $21.73 \pm 8.22$ & $39.51 \pm 5.29$ & $0.1403 \pm 0.03$ & $11.95 \pm 0.81$ & $51.30 \pm 6.92$ \\
\hline Basketball $(\mathrm{n}=40)$ & $10.91 \pm 0.83$ * & $22.86 \pm 9.02$ & $48.59 \pm 7.58^{*}$ & $0.1045 \pm 0.02^{*}$ & $10.15 \pm 1.06^{*}$ & $61.14 \pm 6.04^{*}$ \\
\hline Volleyball $(\mathrm{n}=40)$ & $10.47 \pm 0.62^{\star} \#$ & $19.75 \pm 6.13$ & $50.28 \pm 7.11^{*}$ & $0.1320 \pm 0.03 \#$ & $10.70 \pm 1.03 * \#$ & $59.29 \pm 6.51^{*}$ \\
\hline
\end{tabular}

Data are Mean \pm SD

${ }^{*} p<0.05$ when compared with the sedentary control group

$\# p<0.05$ when compared between basketball and volleyball group

Table 3: Body Composition of the different groups of subjects.

\begin{tabular}{|c|c|c|c|c|c|c|}
\hline Groups & $\begin{array}{l}\text { Sum of skinfolds } \\
\qquad(\mathrm{mm})\end{array}$ & $\begin{array}{l}\text { Body Density } \\
\text { (gm/cc) }\end{array}$ & $\%$ Body Fat (\%) & \% LBM (\%) & $\begin{array}{l}\text { LBM } \\
(\mathrm{kg})\end{array}$ & $\begin{array}{l}\text { Fat Mass } \\
\qquad(\mathrm{kg})\end{array}$ \\
\hline Sedentary $(n=30)$ & $36.23 \pm 9.92$ & $1.065 \pm 0.008$ & $14.64 \pm 3.54$ & $87.75 \pm 4.53$ & $51.60 \pm 7.72$ & $8.99 \pm 3.09$ \\
\hline Basketball $(n=40)$ & $42.80 \pm 15.10$ & $1.061 \pm 0.010$ & $16.76 \pm 4.57$ & $83.24 \pm 4.57$ * & $59.11 \pm 6.34^{*}$ & $12.27 \pm 4.67$ * \\
\hline Volleyball $(n=40)$ & $34.99 \pm 10.78$ & $1.066 \pm 0.009 \#$ & $14.35 \pm 3.89 \#$ & $85.65 \pm 3.89$ \# & $56.83 \pm 6.87^{*}$ & $9.87 \pm 3.84 \#$ \\
\hline
\end{tabular}

LBM $=$ Lean body mass

Data are Mean \pm SD

${ }^{*} p<0.05$ when compared with the sedentary control group

$\# p<0.05$ when compared between basketball and volleyball group

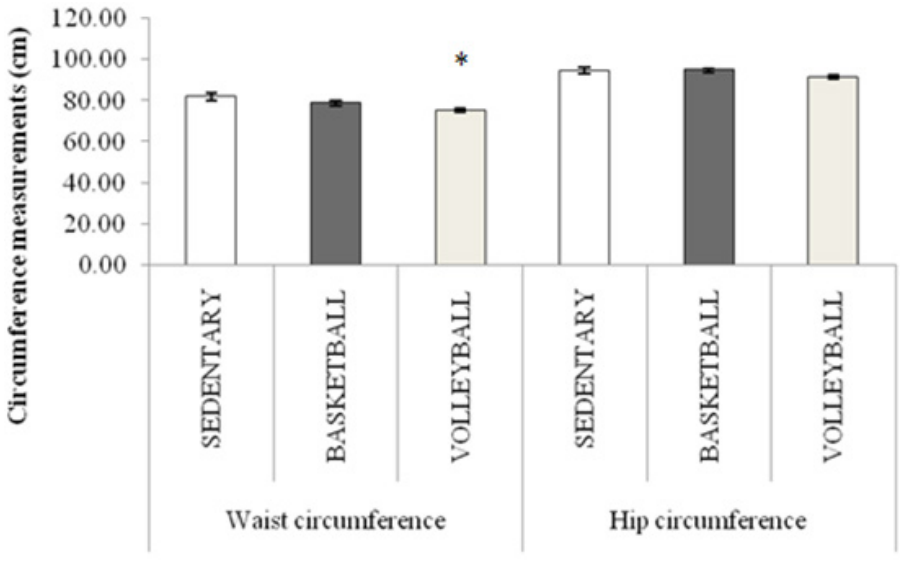

Figure 1: Circumference measurements in the studied population. (*denotes significant at $\mathrm{p}<0.05$ when compared with the sedentary control group)

\section{DISCUSSION}

The present study principally tried to address the objective of evaluating certain selective fitness profile parameters in case of court sport athletes such as basketball players and volleyball players and to compare their data not only between them but also with their sedentary counterparts.

It was found that the physical characteristics related to body height, body weight and BSA differed markedly in case of the basketball and volleyball players when compared against their age-matched, healthy sedentary counterparts. Both the body height and body weight of the basketball and volleyball players in the present study were lower than that of the North Indian players associated with these court sports, as reported earlier. ${ }^{[15]}$ However, these players were found to be considerably shorter and lighter when compared with their international counterparts. ${ }^{[16-18]}$ It was also observed that the basketball players were essentially heavier and

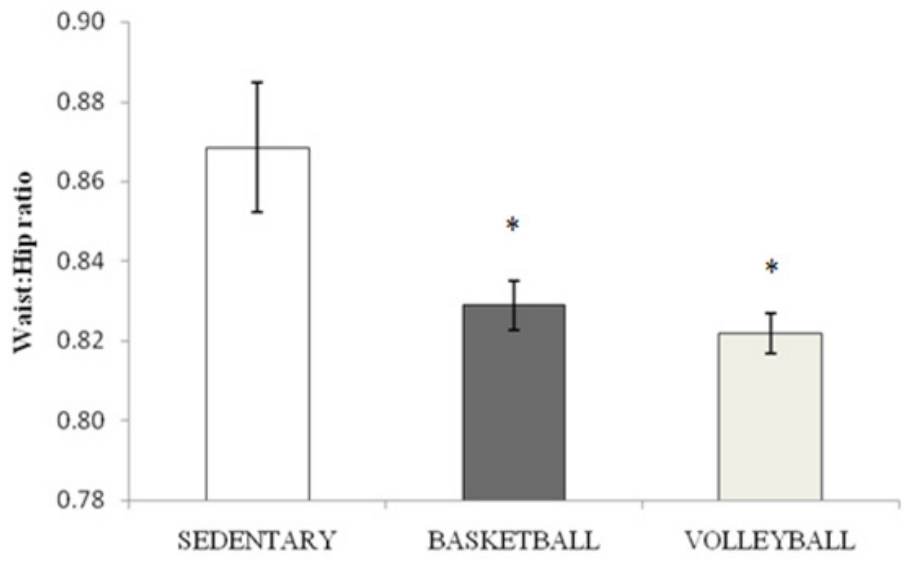

Figure 2: Waist:Hip ratio in the studied population. ( ${ }^{*}$ denotes significant at $p<0.05$ when compared with the sedentary control group)

taller than the volleyball players that may be corroborated with reports from other findings in Turkish and Malaysian athletes. ${ }^{[16,19]}$ Athletes of both these team court sports are required to handle the ball above their head and therefore having greater height is an advantageous factor in these games. ${ }^{[20]}$ The significant intra-group variation in BMI for the basketball and volleyball players may be attributed to the greater body height and body weight in the basketball players. Further, the significantly less waist:hip ratio (WHR) for both the basketball and volleyball players compared to their sedentary counterparts might be reflective of better health condition in the athletic groups (Figure 2 and Figure 3). WHR is significantly associated with cardiac stroke, ischemic heart disease, hypertension, gall bladder disease and menstrual abnormality. ${ }^{[12]}$ It has further become accepted that a high WHR (> 1.0 in men and $>0.85$ in women) indicates abdominal fat accumulation, the potential risk factor of central obesity. ${ }^{[12]}$ The anthropometric characteristics of the volley- 


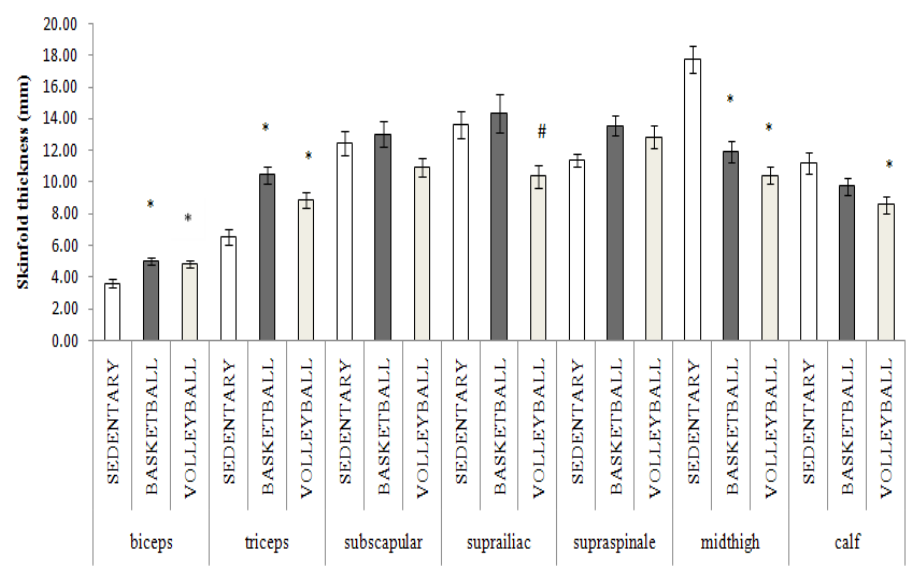

Figure 3: Skinfold measurement in the studied population. ( ${ }^{*}$ denotes significant at $p<0.05$ when compared with the sedentary control group \#denotes significant at $\mathrm{p}<0.05$ when compared between basketball and volleyball group)

ball players were almost similar with the data pertaining to the volleyball athletes from West Bengal. ${ }^{[21]}$

Estimation of body composition may be utilized through quantification of gross size of an individual based on two major structural components such as that of fat mass and lean body mass. ${ }^{[22]}$ It has been mentioned in pertinent literature that the percentage of body fat for the basketball and volleyball players must be within the range of $6 \%-15 \% .{ }^{[23]}$ The present data approximately accords with this view and the percentage of body fat is nearly same with report from earlier study in Indian athletes. ${ }^{[24]}$ Higher percentage of body fat was reflected in case of the basketball players of the present study was noted in comparison with the Greek basketball players and elite French basketball players. ${ }^{[17,18]}$ In games like that of basketball the body has to be propelled horizontally, while for volleyball, in order to deliver movements such as spiking and blocking the players have to move against the gravity. Therefore, increased fat mass might be detrimental to these sport performances as additional fat might add to the body weight thereby making no positive contribution to the energy production or force production. ${ }^{[24]}$ Moreover, the overseas counterparts of the basketball and volleyball players reported to have higher lean body mass. ${ }^{[7,16-18]}$ Greater body density in case of the volleyball players was found to corroborate with earlier finding conducted on North Indian athletes. ${ }^{[24]}$ Further, the presence of significantly higher lean body mass for the volleyball players suggest better health in the athletes and presence of less subcutaneous tissue in contrast to their sedentary counterparts. ${ }^{[15]}$ The inter-group variation between basketball and volleyball groups in terms of the body density, \%fat, fat mass and \%LBM might be due to their difference in training module and dietary pattern (Figure 4).

The present study depicted significantly lower values of pre-exercise heart rate for both the experimental groups compared against their control group counterparts. Better aerobic capacity is often accorded with the presence of lower resting heart rate. ${ }^{[25]}$ Long-term physical training is found to influence the cardiac rhythm through induction of sinus bradycardia in resting conditions, in addition to a slower rise in heart rate at any level of submaximal oxygen uptake due to a swing of the sympathovagal balance towards parasympathetic dominance. ${ }^{[26,27]}$ This phenomenon may be attributed to the presence of significantly lower resting heart rate in the athletic groups. Both the basketball and volleyball players were found to have significantly higher $\mathrm{VO}_{2}$ max in comparison with the sedentary group. The $\mathrm{VO}_{2}$ max of the basketball players in the present study was higher than that of Serbian elite basketball players and South Indian basketball players from Andhra Pradesh. ${ }^{[28,29]}$ Present $\mathrm{VO}_{2}$ max

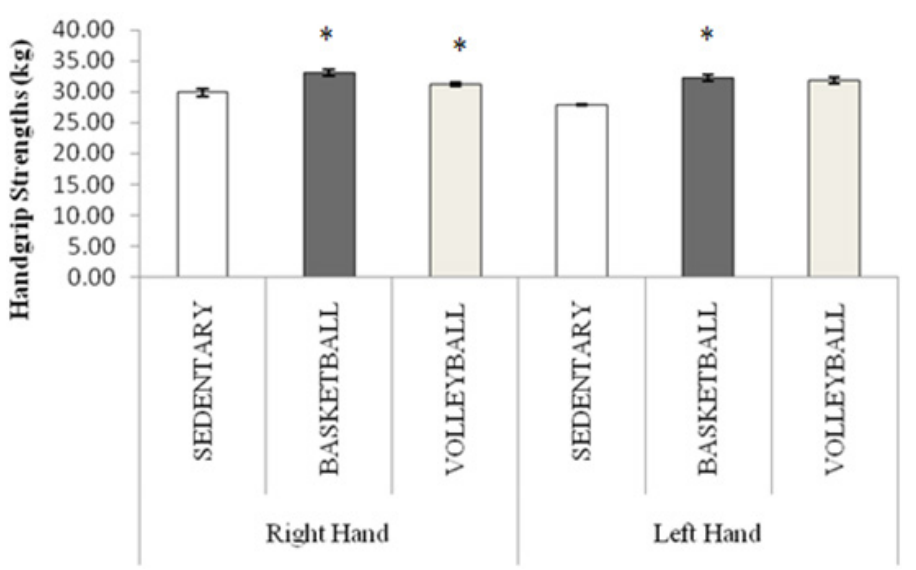

Figure 4: Handgrip Strength of the right hand and left hand in the studied population.

(*denotes significant at $\mathrm{p}<0.05$ when compared with the sedentary control group)

data of the basketball and volleyball players corroborated with the earlier report. ${ }^{[30]}$

Handgrip strength is considered as an important criterion to perform the game specific movements in team court sports like basketball and volleyball. The right handgrip strengths of both the basketball and volleyball players were significantly higher compared to their sedentary counterparts (Figure 4). This might be due to the fact that the right hand being more dominant in most individuals depicted higher values. However, the values were lower than what have been reported in previous studies for the volleyball players in the Indian context. ${ }^{[31,32]}$

Anaerobic power is the ability to overcome heavy resistance with high speed. In the currently studied athletic groups, the energy for the muscle contraction is primarily obtained through the breakdown of phosphagens (adenosine tri-phosphate i.e. ATP and creatinine phosphate i.e. $\mathrm{CP}) .{ }^{[33]}$ Both the athlete groups represented significantly better anaerobic power in contrast to the sedentary control group that in turn might be attributed to their training regime contributing towards positive health benefits. Further, the basketball group showed significantly better anaerobic power when compared with the volleyball group. Pertinent research has highlighted that the coordinative skills concerning an athletic performance get affected due to the physical structure of playing or even due to the training surface. This in turn might result in the change in the amount of the recoil energy that rebound from the surface and reach onto the athlete. ${ }^{[34]}$ Study has revealed that the tartan surface in contrast to natural grass and wooden parquet surface is most suitable for improving the anaerobic power in case of athletes. ${ }^{[35]}$ Therefore, the reason for the difference in anaerobic power in the basketball group and volleyball group might be attributed to the training surfaces, whereby the basketball group practised in the synthetic court turf while the volleyball group practised in natural grass.

The reaction time in case of the basketball players was significantly better as compared to their sedentary counterparts. This has agreement with previous study findings where better reaction time has been reported with respect to the sedentary individuals. ${ }^{[36-38]}$ Further, an inter-group variation in this variable was noted between the experimental groups. Reaction time acts as a reliable indicator of rate of processing of sensory stimuli by central nervous system and its execution in the form of motor response. ${ }^{[39]}$ Thus, it is evident from the present data that the basketball players possessed better reaction time possibly due to the needs and practice of their game. 
The study also revealed better agility scores for both the basketball and volleyball players compared to the sedentary group individuals. The generalized and relatively stabilized pattern of motor control and regulation process are expressed in terms of agility or coordinative abilities. ${ }^{[40]}$ The techniques adopted in each of the games ranging from dribbling, tackling, passing, shooting or laying for basketball and blocking, spiking in case of volleyball might be the attributing factors towards improvement of motor ability in the presently studied experimental groups.

The flexibility component however did not show any significant difference in the studied population. Contrarily, the explosive power as represented through VJT scores was significantly higher in case of both the basketball and volleyball players in comparison to their sedentary group. High-intensity and intermittent nature of team court sports like that of basketball and volleyball require extensive skills and game specific attributes to excel. Thus, the power outputs related to these games was probably associated with muscular strength that in turn attributed to the precision in movements. ${ }^{[41]}$ Better explosive power for the basketball players might be assigned to the game specific demands where the players had to jump to a considerable height for shooting the ball in both the events. ${ }^{[42,43]}$ For volleyball, the players are required to jump for setting, blocking and spiking thereby having the need to jump at a greater height. ${ }^{[44]}$ Moreover, in corroboration with earlier report, it may be said that the Indian volleyball athletes showed inferior values in terms of the performance characteristics such as speed, flexibility (trunk), abdominal strength and strength endurance, agility than Olympic teams. ${ }^{[45]}$ Therefore, it may be said that both these team court sports of basketball and volleyball lead to improvement of the overall fitness profile of the athletes in contrast to the sedentary group individuals.

\section{CONCLUSION}

The study revealed significant differences in some of the anthropometric and fitness profile parameters between the basketball and volleyball players. Basketball players had higher BMI, \%body fat and total fat than volleyball players while body density and \%LBM were higher among volleyball players. Basketball players had better anaerobic power whereas agility score was better in volleyball players. Comparison of basketball players with sedentary control counterparts depicted significantly higher body height, body weight, BSA, both right and left hand handgrip strengths, $\mathrm{VO}_{2} \max , \mathrm{LBM}$, total fat, reaction time, agility, explosive power, anaerobic power and significantly lower resting heart rate, systolic blood pressure, Waist-Hip ratio and \%LBM. Volleyball players had significantly higher body height, body weight, BSA, left hand handgrip strength, explosive power, agility, anaerobic power, $\mathrm{VO}_{2} \max$ and $\mathrm{LBM}$ and significantly lower resting heart rate, diastolic blood pressure, waisthip ratio and \%LBM than age matched healthy controls. The findings are attributed to the training induced adaptations in both the experimental groups and the present data would serve as the national reference database of the basketball and volleyball players.

\section{ACKNOWLEDGEMENT}

The authors are immensely grateful to the players and the authorities of the various sport academies and clubs without whose consent and kind cooperation, the execution of the study would have been impossible. We are also indebted to Mr. Subhashis Ghosh for his unconditional support and necessary assistance in completion of the project.

\section{CONFLICT OF INTEREST}

The authors declare no conflict of interest.

\section{ABBREVIATIONS}

VJT: Vertical Jump Test; BSA: Body Surface Area; BMI: Body Mass Index; BD: Body Density; WHR: Waist-Hip Ratio; HIE: High-Intensity Effort; LBM: Lean Body Mass; FM: Fat Mass; ATP: Adenosine Tri-Phosphate; CP: Creatinine Phosphate.

\section{REFERENCES}

1. Clarke HH. Application of measurement to health and physical education. Prentice Hall. 1967.

2. Tsunawake N, Tahara Y, Moji K, Muraki S, Minowa K, Yukawa K. Body composition and physical fitness of female volleyball and basketball players of the Japan inter-high school championship teams. J Physiol Anthropol Appl Hum Sci. 2003;22(4):195-201. doi: https://doi.org/10.2114/jpa.22.195

3. Neto AP, DeCastro CM. Body composition assessment in male basketball players in Brazilian National Basketball League 2003. Braz J Kinanthropom Hum Perfo. 2005;7(1):35-44. doi: https://doi.org/10.5007/\%25x

4. Ziv G, Lidor R. Physical attributes, physiological characteristics, on-court performances and nutritional strategies of female and male basketball players. Sports Med. 2009;39(7):547-68. doi: https://doi.org/10.2165/00007256-20093907000003

5. Gabbett TJ. Do skill-based conditioning games offer a specific training stimulus for junior elite volleyball players?. J Strength Cond Res. 2008;22(2):509-17. doi: 10.1519/JSC.0b013e3181634550

6. Smith DJ, Roberts D, Watson B. Physical, physiological and performance differences between Canadian national team and universiade volleyball players. $J$ Sports Sci. 1992;10(2):131-8. doi: https://doi.org/10.1080/02640419208729915

7. Ostojic MS, Mazic S, Dikic N. Profiling in basketball: Physical amd physiological characteristics of elite players. J Strength Cond Res. 2006;20(4):740-4. doi: 10.1519/R-15944.1

8. DuBois DF. A formula to estimate the approximate surface area if height and body mass be known. Arch Intern Med. 1916;17:863-71.

9. Roy AS, Dalui R, Kalinski M, Bandyopadhyay A. Anthropometric profile, body composition and vertical jump score in boxers and swimmers. Int J Med Med Res. 2015;1(1):49-53. doi: https://doi.org/10.11603/ijmmr.2413-6077.2015.1.2854

10. Durnin JV, Womersley JV. Body fat assessed from total body density and its estimation from skinfold thickness: Measurements on 481 men and women aged from 16 to 72 years. Brit J Nutr. 1974;32(1):77-97. doi: https://doi.org/10.1079/ BJN19740060

11. Siri WE. The gross composition of the body. In Advances in Biological and Medical Physics. Elsevier. 1956;4:239-80. doi: https://doi.org/10.1016/B978-1-48323110-5.50011-X

12. Park K. Park's Textbook of Preventive and Social Medicine. Banarsidas Bhanot Publishers. 2007.

13. Roy AS, Bandyopadhyay A. Effect of Ramadan intermittent fasting on selective fitness profile parameters in young untrained Muslim men. BMJ Open Sport Exerc Med. 2015;1(1):e000020. doi: http://dx.doi.org/10.1136/bmjsem-2015-000020

14. DelRossi G, Malaguti A, DelRossi S. Practice effects associated with repeated assessment of a clinical test of reaction time. J Athl Train. 2014;49(3):356-9. doi: https://doi.org/10.4085/1062-6059-49.2.04

15. Gaurav V, Singh M, Singh S. A comparative study of somatic traits and body composition between volleyball players and controls. J Sci Technol. 2011;4(2):116-8. doi: 10.17485/ijst/2011/v4i2/29945

16. Pelin C, Kürkçüođlu A, Özener B, Canan YA. Anthropometric characteristics of young Turkish male athletes. Coll Anthropol. 2009;33(4):1057-63.

17. Sallet P, Perrier D, Ferret JM, Vitelli V, Baverel G. Physiological differences in professional basketball players as a function of playing position and level of play. J Sport Med Phys Fit. 2005;45(3):291.

18. Apostolidis N, Nassis GP, Bolatoglou T, Geladas ND. Physiological and technical characteristics of elite young basketball players. J Sport Med Phys Fit. 2004;44(2):157.

19. Nudri W, Ismail MN, Zawiah H. Anthropometric measurements and body composition of selected national athletes. Malays J Nutr. 1996;2(2):138-47.

20. Kansal DK. A study of intrasport differences in the physique of Indian University football players. Perspectives in Kinanthropometry. 1986.

21. Bandyopadhyay A. Anthropometry and body composition in soccer and volleyball players in West Bengal, India. J Physiol Anthropol. 2007;26(4):501-5. doi: https://doi.org/10.2114/jpa2.26.501

22. Jackson AS, Pollock ML. Generalized equations for predicting body density of men. Brit J Nutr. 1978;40(3):497-504. doi: https://doi.org/10.1079/BJN19780152

23. Wilmore JH, Costill DL. Physiology of Sports and Exercise. $2^{\text {nd }}$ ed. Human Kinetics, Champaign. 1999

24. Gaurav V, Singh S. Anthropometric characteristics, somatotyping and body composition of volleyball and basketball players. J Phys Educ Sport Manag. 2010; $1(3): 28-32$ 
25. Reilly T, Secher N, Snell P, Williams C. Physiology of sports: An overview. Physiology of Sports. 1990;465-85.

26. Uusitalo AL, Tahvanainen KU, Uusitalo AJ, Rusko HK. Non-invasive evaluation of sympathovagal balance in athletes by time and frequency domain analyses of heart rate and blood pressure variability. Clin Physiol. 1996;16(6):575-88. doi: https://doi.org/10.1111/j.1475-097X.1996.tb00735.x

27. Seals DR, Chase PB. Influence of physical training on heart rate variability and baroreflex circulatory control. J Appl Physiol. 1989;66(4):1886-95. doi: https:// doi.org/10.1152/jappl.1989.66.4.1886

28. Gavrilovic T, Plavsic J, Mirkovic S, Antic M. O-47 Ergospirometry as a part of a modern diagnostic testing in Serbian elite basketball players. Brit J Sport Med. 2016;50(Suppl):A27.2-8. doi: http://dx.doi.org/10.1136/bjsports-2016-097120.47

29. Mallesh A, Suresh TN, Sivakumar VP. Effectiveness of Sports Specific Circuit Training and High Intensity Interval Training on Aerobic Capacity in Male Basketball Players. Int J Clin Skill. 2017;11(6).

30. Mishra MK, Pandey AK, Chaubey D. A comparative study of Vo2 Max among the basketball, football, volleyball and hockey male players. Int J Appl Res. 2015;1(11):245-7.

31. Mandal N, Maity S, Sahu D. A study of Correlations between dominant handgrip strength with some selected anthropometric and physiological characteristics in inter-college male volleyball players of West Bengal, India. Int J Phys Edu Sports Health. 2015;1(5):17-22.

32. Koley S, Singh J, Sandhu JS. Anthropometric and physiological characteristics on Indian inter-university volleyball players. J Hum Sport Exerc. 2010;5(3):38999. doi: http://dx.doi.org/10.4100/jhse.2010.53.09

33. Kraemer WJ, Ratamess NA. Fundamentals of resistance training: Progression and exercise prescription. Med Sci Sports Exerc. 2004;36(4):674-88. doi: 10.1249/01.MSS.0000121945.36635.61
34. Dick FW. Sports training principles. A. and C. Black. 2007.

35. Özen $G, K o c, H$, Aksoy $C$. Long-term effects of different training surfaces on anaerobic power and leg strength in athletes. Kinesiol Slov. 2017;23(1):25.

36. Ghuntla TP, Mehta HB, Gokhale PA, Shah CJ. Auditory reaction time in basketball players and healthy controls. Int Res J Pharm. 2013;4(8):255-6.

37. Palashikar GS, Waghmare PP, Mundewadi AS. Comparative study of auditory reaction time, visual reaction time and agility in basketball players and healthy controls. Indian J Med Res. 2014;3(4):304-7.

38. Kamble P, Daulatabad VS, Baji PS. An appraisal of aerobic capacity, flexibility agility and reaction time in basketball players and age matched controls. Int $J$ Basic Med Sci. 2012;3(1):34-8

39. Solanki J, Joshi N, Shah C, Mehta HB, Gokhle PA. A study of correlation between auditory and visual reaction time in healthy adults. Int J Public Health. 2012;2(2):36-8. doi: 10.5530/ijmedph.2.2.8

40. Singh H. Science of Sports Training DV S Publication. New Delhi. 1991;85.

41. Reilly T, Secher N, Snell P, Williams C. Physiology of sports: An overview. Physiol Sports. 1990;465-85.

42. Drinkwater EJ, Pyne DB, McKenna MJ. Design and interpretation of anthropometric and fitness testing of basketball players. Sports Med. 2008;38(7):56578. doi: https://doi.org/10.2165/00007256-200838070-00004

43. Singh A. Study of physiological body composition and psychomotor variables of basketball players at different levels of competition. 2012;1-22.

44. Marques MC, Marinho DA. Physical parameters and performance values in starters and non-starters volleyball players: A brief research note. Motricidade. 2009;5(3):7-11. doi: https://doi.org/10.6063/motricidade.189

45. Das SS, Biswas KA, Sarkar A. Physical and Performance Characteristics of Indian Elite Volleyball Players. Int J Health Phys Educ Comp Sci Sports. 2011;2(1):11

Cite this article: Basu S, Roy AS, Dalui R, Bandyopadhyay A. Physical Fitness of Basketball and Volleyball Players of Kolkata, India. Int J Clin Exp Physiol. 2019;6(4):111-7. 